\title{
SOME REMARKS TO ONE SELF-NEUTRALIZATION MODEL OF BEAMS
}

\author{
J. Pivarč* Institute of Physics, SAS, SK-842 28 Bratislava, Slovakia \\ A. Tikhomirov, Joint Institute for Nuclear Research, FLNR, 141980 Dubna, Russia
}

\begin{abstract}
This paper gives some new results to one selfneutralization model of beams. The main attention is concentrated to influences of the ratio of (plasma potential)/(temperature of electrons) on the beam density and losses of protons, respectively. The loss of protons transmitted inside beam chamber due to charge changing collisions with the residual gas molecules is discussed for nine different pressure regions of $1-10^{-9} \mathrm{~Pa}$.
\end{abstract}

\section{INTRODUCTION}

The neutralization effects are a limitation of accelerator performances at various occasions. Some of the difficulties of the first accelerators came from the fact that vacuum systems were not good enough. The difficulties would be rather be linked at the large currents and high densities especially of the circulating beams.

\section{ONE SELF-NEUTRALIZATION MODEL OF BEAM}

One self-neutralization model of beam has been published in papers [1 - 3]. It is assumed that the electron production is mainly due to the collisions between beam ions and gas atoms and electron loss is due to scattering out of the potential well of the beam. The electron production rate is given by

$$
\frac{d n_{e}}{d t}=n_{i} n_{o} \sigma_{i o} v_{i}
$$

and the electron loss rate is given by

$$
-\frac{d n_{e}}{d t}=\frac{n_{e}}{\tau} e^{-\frac{\Phi}{T}}
$$

where $n_{i}$ is the ion beam density, $n_{o}$ is the neutral density, $\sigma_{i o}$ is the cross section for ionization of the atoms by the beam ions, $v_{i}$ is the ion beam velocity, $n_{e}$ is the electron density, $\tau$ is time of scattering of electrons by the ions inside the beam, $\Phi$ is the plasma potential and T is the electron temperature. The quantities $\Phi$ and $\mathrm{T}$ are expressed in the same units.

The energy input is estimated from the heating rate of the electrons by the beam ions as $n_{e} m_{e} v_{i}^{2} / 2 \tau$, where $m_{e}$ is

\footnotetext{
*fyzipiv@savba.sk
}

the electron mass. Hamilton [2] calculates the energy loss from the system by means of the ionization cross section $\sigma_{i o}$, charge exchange cross section $\sigma_{x}$ and transport potential energy $\Phi$ from the system. He derived for the energy loss rate $n_{i} n_{o} v_{i}\left(\sigma_{i o}+\sigma_{x}\right) \Phi$.

Finally, we assume that the beam ion density $n_{i}$ is approximately the same as the electron density $n_{e}$, i.e. $n_{e} \approx$ $n_{i}$. The effect of slow ions is also neglected completely. After that the two equations for particle and power balance can be reduced to the form

$$
n_{i} \sigma_{i o} v_{i}=\frac{1}{\tau} e^{-\frac{\Phi}{T}}
$$

and

$$
n_{o}\left(\sigma_{i o}+\sigma_{x}\right) v_{i} \Phi=\frac{m_{e} v_{i}^{2}}{2 \tau} .
$$

Further $W=\frac{M v_{i}^{2}}{2}=e V$, where $e V$ is the energy and $M$ is the mass of ions, respectively. Hence the ratio $\Phi / T$ can be calculated from

$$
\frac{\Phi}{T}=2.3 \log \left(\frac{M}{m_{e}} \frac{\Phi}{e V} \frac{\sigma_{i o}+\sigma_{x}}{\sigma_{i o}}\right) .
$$

Typical parameters of the hydrogen beam at the energy $\mathrm{W}$ $=20 \mathrm{keV}$ and the pressure $\mathrm{p}=10^{-7} \mathrm{~Pa}\left(\mathrm{p}=n_{o} k T\right)$ are

$$
\begin{aligned}
& \mathrm{J}=0.1 \mathrm{~mA} \mathrm{~cm}^{-2} \quad \mathrm{v}_{i}=1.9 \times 10^{8} \mathrm{~cm} \mathrm{~s}^{-1} \\
& \mathrm{n}_{i}=4.46 \times 10^{6} \text { ions cm } \mathrm{cm}^{-3} \quad \mathrm{n}_{o}=2.645 \times 10^{7} \mathrm{~cm}^{-3} \\
& \sigma_{i o}=0.2 \times 10^{-16} \mathrm{~cm}^{2} \quad \sigma_{x}=4.3 \times 10^{-16} \mathrm{~cm}^{2}
\end{aligned}
$$

and the ratio $\Phi / \mathrm{T}$ is

$$
\frac{\Phi}{T}=10.62+2.3 \log \left(\frac{\Phi}{W}\right) .
$$

One can see that for the temperature of electrons $\mathrm{T}_{e}=3.3$ $\mathrm{eV}$ and the energy $\mathrm{W}=20 \mathrm{keV}$ the potential $\Phi$ is about close $10 \mathrm{eV}$.

If $\sigma_{i o} \longrightarrow \infty$ and $\sigma_{x}-\rightarrow 0$ the logarithmic equation (5) for the ratio $\Phi / \mathrm{T}$ takes the form

$$
\frac{\Phi}{T}=2.3 \log \left(\frac{M}{m_{e}} \frac{\Phi}{W}\right) .
$$

The correction terms appear in the logarithmic form and therefore do not produce a large effect.

The electrons produced in ionization have, in general, a final energy of several electronvolts, which must contribute to the energy input. Also it can be argued that the energy transported away from the system by the cold ions comes from the beam ions directly and not from the electron gas. 
The assumption of quasi-neutrality, which is conditioned by relation $n_{i} \approx n_{e}$, is also conserved when the beam density $\mathrm{J}\left(\mathrm{J}_{o}=n_{i} v_{i}\right)$ is introduced by equations

$$
\begin{gathered}
\mathrm{J}=\frac{0.1 \mathrm{~J}_{\mathrm{o}}}{6.242 \times 10^{18}} \\
\mathrm{~J}_{o} n_{o} \sigma_{i o}=\frac{n_{e}}{\tau} e^{-\frac{\Phi}{T}} \\
\frac{1}{\tau}=\frac{2 n_{o} \Phi}{m_{e} v_{i}}\left(\sigma_{i o}+\sigma_{x}\right)
\end{gathered}
$$

or

$$
J=1.6 \times 10^{-20} n_{e} v_{i} \frac{M}{m_{e}}\left(\frac{\sigma_{i o}+\sigma_{x}}{\sigma_{i o}}\right) \frac{\Phi}{W} e^{-\frac{\Phi}{T}}
$$

where $\mathrm{J}$ is given in $\left(\mathrm{mA} \mathrm{cm}{ }^{-2}\right)$ and other quantities are given in SI units. Knowing the energy of protons $\mathrm{W}=20$ $\mathrm{keV}, \mathrm{M} / m_{e}=1836.151, v_{i}=1.9 \times 10^{8} \mathrm{~cm} \mathrm{~s}^{-1}$ and $\mathrm{n}_{e}=$ $4.46 \times 10^{6}$ electrons $\mathrm{cm}^{-3}$, the solution becomes much simpler

$$
J=0.28 \Phi e^{-\frac{\Phi}{T}}
$$

where $\Phi$ and $\mathrm{T}$ are given in $(\mathrm{eV})$ and $\mathrm{J}$ is given in $(\mathrm{mA}$

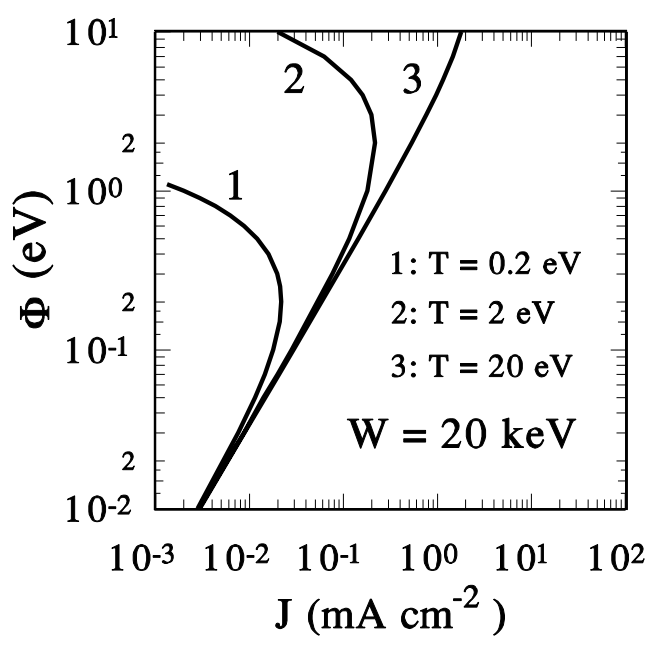

Figure 1: Beam potential $\Phi$ in dependence from density of protons for three different electron temperatures $\mathrm{T}(1: \mathrm{T}=$ $0.2 \mathrm{eV} ; 2: \mathrm{T}=2 \mathrm{eV} ; 3: \mathrm{T}=20 \mathrm{eV})$ at the energy of protons $\mathrm{W}=20 \mathrm{keV}$.

$\mathrm{cm}^{-2}$ ). In order to illustrate the results of the last two equations Figs. 1 and 2 are shown.

By comparing of the basic equations (1) and (2) and the derivative $d n_{i} / d t$ one can obtain

$$
-\frac{d n_{i}}{d t}=\frac{1}{\tau n_{o} \sigma_{i o} v_{i}} e^{-\frac{\Phi}{T}}\left(-\frac{d n_{e}}{d t}\right) .
$$

By means of the relations (2) and (4) one gets

$$
-\frac{d n_{i}}{d t}=\frac{1}{k T_{a}} n_{e} p v_{i} \frac{\left(\sigma_{i o}+\sigma_{x}\right)^{2}}{\sigma_{i o}}\left(\frac{M \Phi}{m_{e} W}\right)^{2} e^{-\frac{2 \Phi}{T}}
$$

where all quantities are in SI units.
Using just this ratio one can see the linear dependence of the proton losses on the pressure of residual gas. By substituting $\mathrm{T}_{a}=20{ }^{\circ} \mathrm{C}, \mathrm{M} / m_{e}=1836.151, \mathrm{~m}_{e}=9.1095 \times 10^{-31}$ $\mathrm{kg}, v_{i}=1.385 \times 10^{4}[\mathrm{~W}(\mathrm{eV})]^{1 / 2} \mathrm{~m} \mathrm{~s}^{-1}, n_{e}=4.46 \times 10^{12}$ electrons $\mathrm{m}^{-3}, \sigma_{i o}=0.2 \times 10^{-20} \mathrm{~m}^{2}$ and $\sigma_{x}=4.3 \times 10^{-20}$ $\mathrm{m}^{2}$ into equation (13) one can also obtain

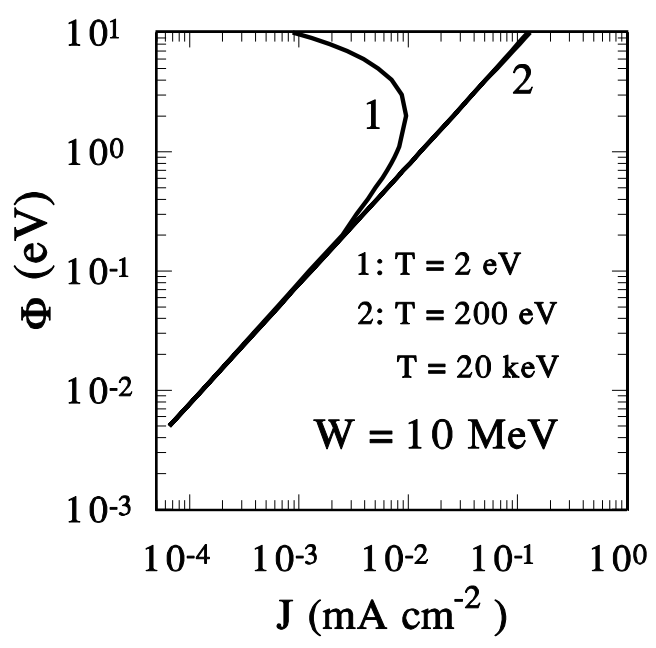

Figure 2: Beam potential $\Phi$ in dependence from density of protons for three different electron temperatures $\mathrm{T}(1: \mathrm{T}$ $=2 \mathrm{eV} ; 2: \mathrm{T}=200 \mathrm{eV}$ and $\mathrm{T}=20 \mathrm{keV}$ ) at the energy of protons $\mathrm{W}=10 \mathrm{MeV}$. Curve 2 coincides (within the given scale) with that of $\mathrm{T}=20 \mathrm{keV}$.

$$
-\frac{d n_{i}}{d t}=5.2 \times 10^{25} p \frac{\Phi}{W} \frac{\Phi(e V)}{\sqrt{W(e V)}} e^{-\frac{2 \Phi}{T}}
$$

where the pressure $\mathrm{p}(\mathrm{Pa})$ and the loss rate $\left(\mathrm{d} n_{i} / \mathrm{dt}\right)$

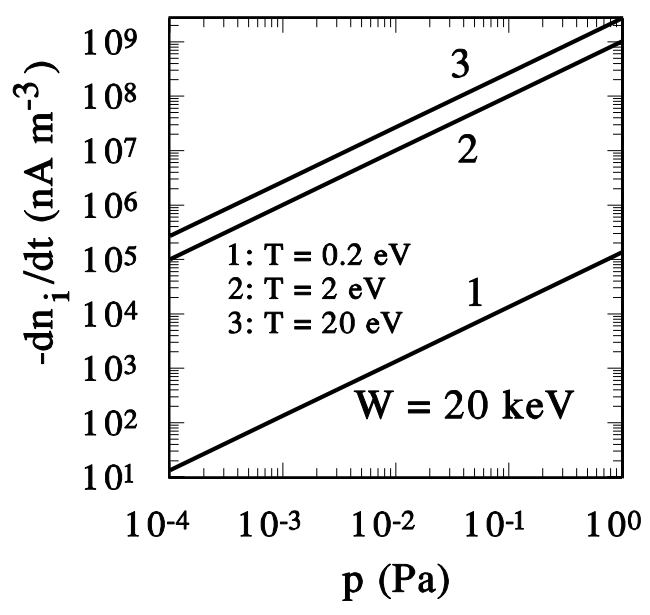

Figure 3: Proton beam losses $\left(-\mathrm{d} n_{i} / \mathrm{dt}\right)$ as a function of pressure $\mathrm{p}\left(1-10^{-4}\right) \mathrm{Pa}$ into beam lines and chambers for three different electron temperatures $\mathrm{T}(1: \mathrm{T}=0.2 \mathrm{eV} ; 2$ : $\mathrm{T}$ $=2 \mathrm{eV} ; 3: \mathrm{T}=20 \mathrm{eV}$ ) and at the energy of protons $\mathrm{W}=20$ $\mathrm{keV}$. 
(protons $\mathrm{m}^{-3} \mathrm{~s}^{-1}$ ). In order to illustrate results of equations (14 - 15) Figs. 3 to 6 are shown.

\section{DISCUSSION}

Figs. 1 and 2 show that the beam potential energy $\Phi$ varies from about $5 \times 10^{-3} \mathrm{eV}$ to $10 \mathrm{eV}$ at the electron energies T: $0.2 \mathrm{eV} ; 2 \mathrm{eV} ; 20 \mathrm{eV}(\mathrm{W}=20 \mathrm{keV}) ; \mathrm{T}: 2 \mathrm{eV} ; 200 \mathrm{eV}$; $20 \mathrm{keV}(\mathrm{W}=10 \mathrm{MeV})$ and at the different beam densities $\mathrm{J}\left(10^{-4}<\mathrm{J}<10^{-1} \mathrm{~mA} \mathrm{~cm}^{-2}\right)$. It is also seen a maximum of the beam density $\mathrm{J}$ for the given beam potential $\Phi$ at the electron energies T: $0.2 \mathrm{eV} ; 2 \mathrm{eV}(\mathrm{W}=20 \mathrm{keV})$ and $2 \mathrm{eV}$

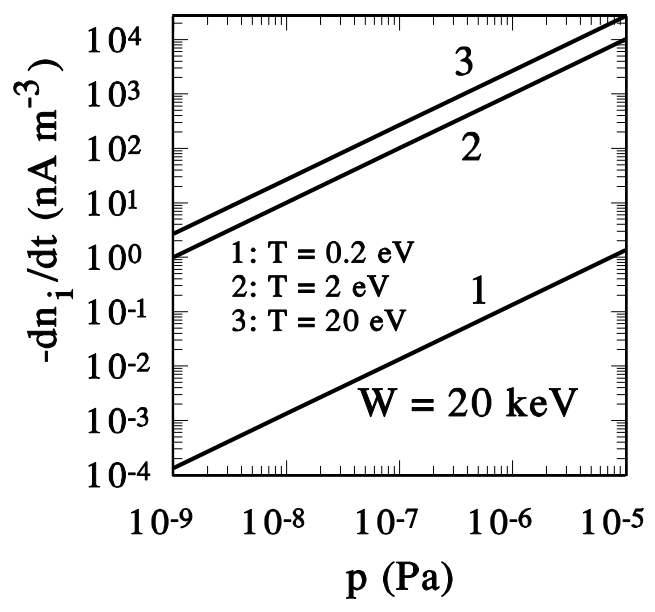

Figure 4: Proton beam losses $\left(-\mathrm{d} n_{i} / \mathrm{dt}\right)$ as a function of pressure $\mathrm{p}\left(10^{-5}-10^{-9}\right) \mathrm{Pa}$ inside beam lines and chambers for three different electron temperatures $\mathrm{T}(1: \mathrm{T}=0.2$ $\mathrm{eV} ; 2: \mathrm{T}=2 \mathrm{eV} ; 3: \mathrm{T}=20 \mathrm{eV}$ ) and at the energy of protons $\mathrm{W}=20 \mathrm{keV}$.

( $\mathrm{W}=10 \mathrm{MeV}$ ), respectively.

The proton beam loss rates shown in Figs. 3 to 6 have been calculated from the relation

$$
-\frac{d n_{i}}{d t}\left(\mathrm{nA} \mathrm{m}^{-3}\right)=\mathrm{Ax} 10^{\mathrm{B}} \mathrm{p}(\mathrm{Pa})
$$

which is derived from the equation (14), where the characteristic values $\mathrm{A}$ and $\mathrm{B}$ are: $\mathrm{A}=1.33, \mathrm{~B}=5$ for $\mathrm{T}=0.2 \mathrm{eV}$; $\mathrm{A}=1.08, \mathrm{~B}=9$ for $\mathrm{T}=2 \mathrm{eV} ; \mathrm{A}=2.66, \mathrm{~B}=9$ for $\mathrm{T}=20$ $\mathrm{eV}(\Phi=1 \mathrm{eV}, \mathrm{W}=20 \mathrm{keV}) ; \mathrm{A}=9.69, \mathrm{~B}=4$ for $\mathrm{T}=2 \mathrm{eV}$; $\mathrm{A}=2.6, \mathrm{~B}=5$ for $\mathrm{T}=200 \mathrm{eV}$ and $\mathrm{A}=2.63, \mathrm{~B}=5$ for $\mathrm{T}=$ $20 \mathrm{keV}(\Phi=1 \mathrm{eV}, \mathrm{W}=10 \mathrm{MeV})$, respectively.

Based on the values shown in Figs. 3 to 6 it is seen that the proton beam loss rates $\left(-\mathrm{dn}_{i} / \mathrm{dt}\right)$ increase with increasing pressure $\mathrm{p}$ and energy of electrons $\mathrm{T}$. In the case of energy of electrons T: $0.2 \mathrm{eV} ; 20 \mathrm{eV}(\mathrm{W}=20 \mathrm{keV})$ (Fig. 3) the difference between the proton beam loss rates is about $2.4 \times 10^{9} \mathrm{nA} \mathrm{m}^{-3}$ at the pressure $1 \mathrm{~Pa}$. The differences are considerably less at pressures of $10^{-4} \mathrm{~Pa}\left(2.4 \times 10^{5} \mathrm{nA}\right.$ $\mathrm{m}^{-3}$; Fig. 3), $10^{-5} \mathrm{~Pa}\left(2.4 \times 10^{4} \mathrm{nA} \mathrm{m}^{-3}\right.$; Fig. 4) or $10^{-8}$ $\mathrm{Pa}\left(25 \mathrm{nA} \mathrm{m}^{-3}\right.$; Fig. 4), respectively. The proton beam loss rates are relatively small not only at the energy of protons $\mathrm{W}=20 \mathrm{keV}$ but also at the energy of protons $\mathrm{W}=10$
$\mathrm{MeV}$ (Figs. 5 to 6). In general, comparing data in Figs. 3 to 6 one can see that the higher is the energy of protons the smaller are their losses at the same residual gas pressures.

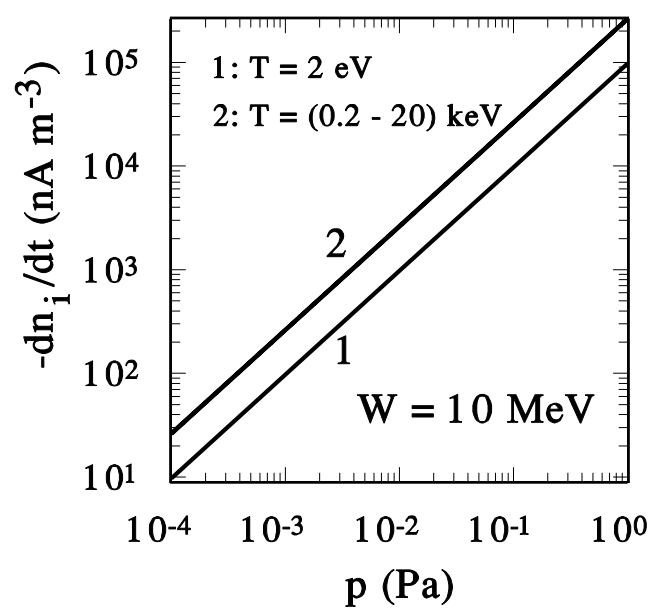

Figure 5: Proton beam losses $\left(-\mathrm{d} n_{i} / \mathrm{dt}\right)$ as a function of pressure $\mathrm{p}\left(1-10^{-4}\right) \mathrm{Pa}$ inside beam lines and chambers for different electron temperatures $\mathrm{T}(1: \mathrm{T}=2 \mathrm{eV} ; 2: \mathrm{T}=$ $(0.2-20) \mathrm{keV})$ and at the energy of protons $\mathrm{W}=10 \mathrm{MeV}$.

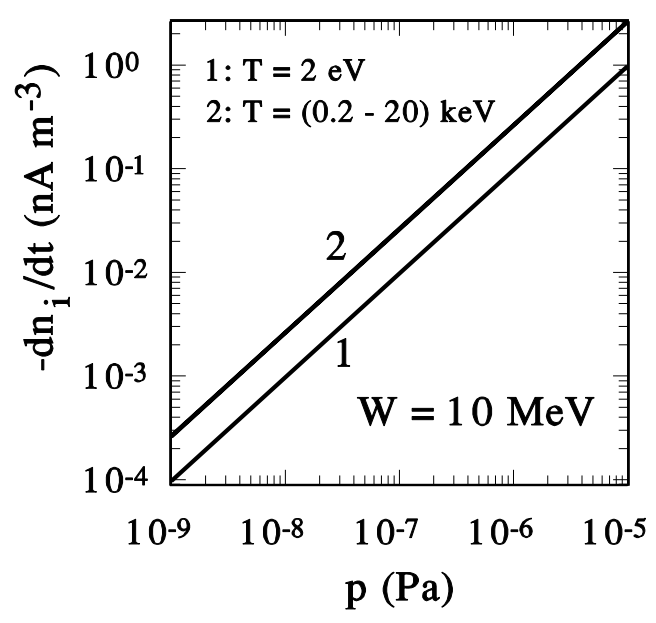

Figure 6: Proton beam losses $\left(-\mathrm{d} n_{i} / \mathrm{dt}\right)$ as a function of pressure $\mathrm{p}\left(10^{-5}-10^{-9}\right) \mathrm{Pa}$ inside beam lines and chambers for different electron temperatures $\mathrm{T}(1: \mathrm{T}=2 \mathrm{eV} ; 2$ : $\mathrm{T}=(0.2-20) \mathrm{keV})$ and at the energy of protons $\mathrm{W}=10$ $\mathrm{MeV}$.

\section{REFERENCES}

[1] G.W. Hamilton, Proc. of Symp. of Ion Sources, Brookhaven, BNL 50310, 1971, p. 71.

[2] T.S. Green, Reports on Progress in Physics 37 (1974) 1257.

[3] J. Pivarč, J. Pivarč, jun., Proc. of the $12^{\text {th }}$ Conf. of Czech and Slovak Physicists, Ostrava 2-6 Sept., 1996. Eds. M. Lesňák, J. Luňáček, J. Pištora (Ostrava University, CZ-70833 Ostrava, 1966, Czech Republic), p. 228. 